Jurnal Kesehatan 14 (2) 2021, 223-229

\title{
Faktor Biososial Kualitas Hidup Pada Anak Cerebral Palsy
}

\author{
Alinda Nur Ramadhani ${ }^{1}$, Dea Linia Romadhoni ${ }^{2}$ \\ 1,2 Program Studi Fisioterapi, Fakultas Ilmu Kesehatan, Universitas ‘Aisyiyah Surakarta, Jawa Tengah, \\ Indonesia \\ Jl. Ki Hajar Dewantara 10, Kentingan, Jebres, Surakarta \\ 57126, Jawa Tengah, Indonesia \\ Email: ${ }^{1}$ alinda.ramadhanii@gmail.com ; ${ }^{2}$ dealiniafisio@gmail.com
}

Tanggal Submisi: 20 September 2020 ; Tanggal Penerimaan: 22 Juni 2021

\begin{abstract}
ABSTRAK
Cerebral Palsy (CP) merupakan salah satu penyebab paling umum dari disabilitas fisik pada masa kanak-kanak. Cerebral palsy sering dikaitkan dengan berbagai masalah muskuloskeletaal, gangguan emosi, perilaku, sensoris, dan kognitif. Berbagai permasalahan ini mungkin berefek negatif terhadap kualitas hidup anak Cerebral palsy. Tujuan dari penelitian ini adalah untuk menganalisis faktor biososial yang berhubungan dengan kualitas hidup anak cerebral palsy. Penelitian ini menggunakan studi analitik observasional dengan pendekatan cross sectional. Sebanyak 110 subyek penelitian diambil menggunakan teknik simple random sampling. Data dikumpulkan dengan menggunakan kuesioner dan dianalisis dengan path analysis. Kualitas hidup anak cerebral palsy berhubungan dengan kemampuan motorik kasar $(b=2,79 ; C I$ 95\% $=1,54$ hingga 4,03; $\mathrm{p}=<0,001)$, dukungan keluarga $(\mathrm{b}=1,25 ; \mathrm{CI} 95 \%=0,26$ hingga 2,24; $\mathrm{p}=<0,013)$, dan dukungan sosial $(b=0,99 ;$ CI 95\% $=0,14$ hingga 1,$97 ; p=<0,047)$. Kesimpulan penelitian ini adalah kualitas hidup anak cerebral palsy berhubungan dengan kemampuan motorik kasar, dukungan keluarga yang kuat dan dukungan sosial yang kuat.
\end{abstract}

Kata Kunci: Kualitas hidup, Cerebral Palsy, faktor biososial.

\begin{abstract}
ABTRACT
Cerebral Palsy is one of the most common causes of physical disability in childhood. Cerebral palsy is often associated with a variety of musculoskeletal problems, emotional, behavior, sensory and cognitive disorders. These various problems may have a negative effect on the quality of life of children with cerebral palsy. This study aimed to analyze the biosocial factors associated with the quality of life among children with cerebral palsy. This study used an observational analytic study with a cross sectional approach. A total of 110 subjects were taken using simple random sampling technique. Data were collected using a questionnaire and analyzed by path analysis. Quality of life children with Cerebral Palsy was related to gross motor function $(b=2.79 ; 95 \% C I=1.54$ to 4.03 ; $p=\langle 0.001)$, family support $(b=1.25 ; 95 \% C I=0.26$ to $2.24 ; p=\langle 0.013)$, and social support $(b$ $=0.99 ; 95 \% C I=0.14$ to $1.97 ; p=<0.047)$. The conclusion of this study is that the quality of life children with cerebral palsy is associated with.
\end{abstract}

Keywords: Quality of life, Cerebral Palsy, biosocial factors.

ISSN 1979-7621 (Print). ISSN 2620-7761 (Online).

DOI 10.23917/jk.v14i2.12861

\section{PENDAHULUAN}

Cerebral palsy didefiniskan sebagai sekumpulan gangguan permanen dari perkembangan gerak dan postur yang menyebabkan keterbatasan aktivitas, yang disebabkan oleh gangguan non progresif pada otak bayi atau janin yang berkembang dan terjadi pada masa kanak-kanak (Rossenbaum et al., 2007; Reddinhough et al., 2013). Cerebral 
Palsy merupakan salah satu penyebab paling umum dari disabilitas fisik pada masa kanakkanak dengan prevalensi sebesar 1,5-2,5 per 1000 kelahiran hidup (Oskui et al., 2013).

Gangguan motorik pada cerebral palsy sering disertai dengan gangguan sensasi, persepsi, kognitif, komunikasi dan perilaku. Gangguan lain yang muncul pada anak dengan cerebral palsy berupa gangguan visual, auditori, bahasa, komunikasi, retardasi mental, epilepsi dan penurunan aktivitas keseharian (Delacy et al., 2016; Jeffries et al., 2016; Reddinhough et al., 2013). Berbagai gangguan tersebut berdampak pada berbagai aspek kehidupan anak termasuk kesehatan fisik, kesejahteraan sosial emosi, partisipasi dalam aktivitas keseharian, dan kualitas hidup (Colver et al., 2014).

Beberapa penelitian mengungkapkan bahwa kualitas hidup anak-anak dan remaja cerebral palsy menunjukkan nilai yang serupa dengan populasi umum kecuali pada domain partisipasi sosial dan fungsi motorik (Colver et al., 2015; Dickinson et al., 2007). Faktor-faktor yang mempengaruhi kualitas hidup anak cerebral palsy sangat multidimensional dan bervariasi mencakup aspek biologi, psikologis, dan sosial (Chen et al., 2014). Stres orangtua, masalah psikologis, nyeri dan gangguan motorik pada anak cerebral palsy diketahui sebagai prediktor yang memperburuk kualitas hidup anak (Colver et al., 2015; Chen et al., 2014).

Penelitian mengenai faktor yang berhubungan dengan kualitas hidup anak cerebral palsy belum banyak dilakukan di Indonesia. Penelitian ini diharapkan dapat menambah pengetahuan dan referensi dalam studi tentang faktor-faktor yang mempengaruhi kualitas hidup anak cerebral palsy. Tujuan dari penelitian ini adalah untuk menganalisis faktor biososial yang berhubungan dengan kualitas hidup anak cerebral palsy.

\section{METODE PENELITIAN}

Desain penelitian yang digunakan adalah survey analitik observasional menggunakan pendekatan cross sectional yang dilakukan di YPAC Surakarta dan PNTC Karanganyar.

Teknik pengambilan sampel pada penelitian ini adalah fixed disease sampling. Fixed disease sampling merupakan teknik sampling berdasarkan status penyakit subyek, dalam hal ini adalah diagnosa cerebral palsy. Total jumlah sampel pada penelitian ini adalah 110 anak cerebral palsy usia 4-12 tahun di YPAC Surakarta dan PNTC Karanganyar.

Variabel pada penelitian ini terdiri dari variabel dependen dan variabel independen. Variabel dependen adalah kualitas hidup anak cerebral palsy, sedangkan variabel independen adalah kemampuan motorik kasar, dukungan keluarga dan dukungan sosial.

Definisi operasional variabel kualitas hidup adalah penilaian dari kesejahteraan subjektif individu yang mencakup bidang kesehatan dan non kesehatan, diukur menggunakan kuesioner CP-QOL (Cerebral Palsy Quality of Life). Kemampuan motorik kasar adalah kemampuan gerak dan koordinasi tubuh yang melibatkan kerja otot-otot besar seperti berdiri, berjalan, berlari, melompat, dan melempar, diukur menggunakan kuesioner GMFM (Gross Motor Function Measurement).

Dukungan keluarga adalah bentuk perilaku yang dilakukan oleh keluarga kepada responden berupa dukungan informasi, emosional, instrumental dan penilaian, diukur menggunakan kuesioner. Dukungan sosial adalah bentuk perilaku yang dilakukan oleh lingkungan sosial seperti saudara, teman dekat, pasangan hidup, rekan kerja, dan tetangga kepada responden, yang berupa dukungan informasi, emosional, instrumental dan penilaian, diukur menggunakan kuesioner.

Variabel penelitian dependen kualitas hidup dikategorikan 0 sebagai kualitas hidup baik dan 1 sebagai kualitas hidup buruk. Variabel independen kemampuan motorik kasar dikategorikan 0 sebagai buruk dan 1 sebagai baik. Tingkat stress orang tua dikategorikan 0 sebagai rendah dan 1 sebagai tinggi. Dukungan keluarga dikategorikan 0 sebagai lemah dan 1 sebagai kuat. Dukungan sosial dikategorikan 0 sebagai lemah dan 1 sebagai kuat. 
Teknik analisis data menggunakan analisis univariat, bivariat, dan multivariat. Analisis univariat bertujuan untuk menjelaskan karakteristik masing-masing variabel. Analisis bivariat bertujuan untuk menganalisis hubungan dua variabel dengan uji chi square. Analisis multivariat menggunakan path analysis untuk mengetahui hubungan variabel independen dengan variabel dependen dan mengetahui besarnya hubungan variabel tersebut

\section{HASIL DAN PEMBAHASAN}

Tabel 1 menunjukkan karakteristik tipe cerebral palsy yaitu spastic $(66,4 \%)$, athetoid $(19,1 \%)$ dan ataxia $(14,5 \%)$. Anak cerebral palsy dengan kualitas hidup baik sebanyak 63 $(56,4 \%)$ dan kualitas hidup buruk sebanyak $48(43,6 \%)$ anak. Anak cerebral palsy dengan kemampuan motorik kasar baik sebanyak $31 \quad(28,2 \%)$ dan kemampuan motorik kasar buruk sebanyak 79 (71,8\%). Anak cerebral palsy dengan dukungan keluarga kuat sebanyak $59(53,6 \%)$ dan dukungan keluarga lemah sebanyak 51 $(46,4 \%)$. Anak cerebral palsy dengan dukungan sosial kuat sebanyak $49(44,5 \%)$ dan dukungan sosial lemah sebanyak 61 $(55,5 \%)$.

Tabel 1. Karakteristik Responden

\begin{tabular}{lcc}
\hline Variabel & n & \% \\
\hline Kualitas Hidup & 62 & 56.4 \\
Baik & 48 & 43.6 \\
Buruk & & \\
Tipe cerebral palsy & 73 & 66.4 \\
Spastic & 21 & 19.1 \\
Athetoid & 16 & 14.5 \\
Ataxia & & \\
Kemampuan Motorik Kasar & 31 & 28.2 \\
Baik & 79 & 71.8 \\
Buruk & & \\
Tingkat Stress Orang Tua & 63 & 57.3 \\
Tinggi & 47 & 42.7 \\
Rendah & & \\
Dukungan Keluarga & 51 & 46.4 \\
Lemah & 59 & 53.6 \\
Kuat & & \\
Dukungan Sosial & 61 & 55.5 \\
Lemah & 49 & 44.5 \\
\hline Kuat & Analisis bivariat menggunakan & uji
\end{tabular}

Analisis bivariat menggunakan uji $C h i$ Square dan perhitungan Odd Ratio (OR) pada masing-masing variabel dependen dan variabel independen. Analisis multivariat menggunakan Path Analysis untuk mengetahui besarnya pengaruh suatu variabel secara langsung maupun tidak langsung.

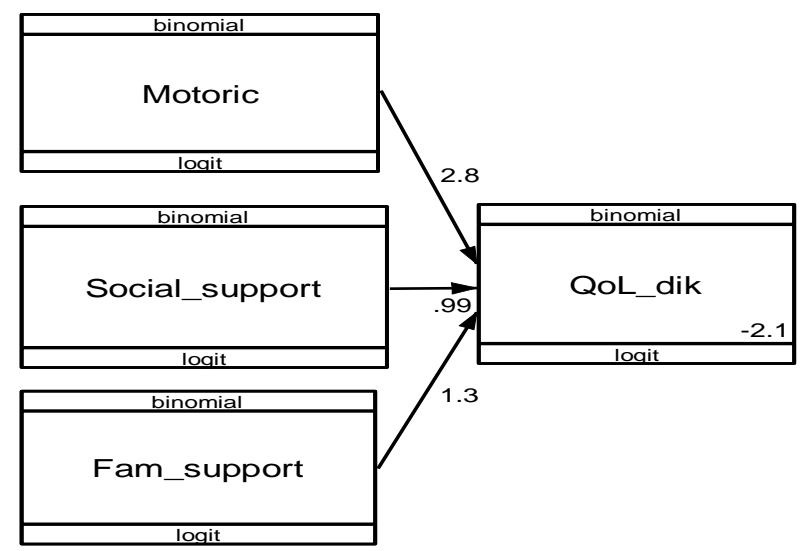

Gambar 1. Model Struktural Path Analysis dengan estimasi 
Tabel 2. Hasil Path Analysis Hubungan Faktor Biososial Kualitas Hidup Anak Cerebral Palsy

\begin{tabular}{|c|c|c|c|c|c|}
\hline \multicolumn{2}{|c|}{ Variabel } & \multirow{2}{*}{$\begin{array}{l}\text { Koefisien } \\
\text { Jalur (b) }\end{array}$} & \multicolumn{2}{|c|}{ CI (95\%) } & \multirow[t]{2}{*}{$\mathbf{P}$} \\
\hline & & & Batas Bawah & Batas Atas & \\
\hline \multicolumn{6}{|l|}{ Direct Effect } \\
\hline Kualitas Hidup $<$ & Dukungan & 1.25 & 0.26 & 2.24 & 0.013 \\
\hline Kualitas Hidup $<$ & Dukungan & 0.99 & 0.01 & 1.97 & 0.047 \\
\hline Kualitas Hidup & $\begin{array}{l}\text { Kemampuan } \\
\text { motorik kasar }\end{array}$ & 2.79 & 1.54 & 4.03 & $<0.001$ \\
\hline
\end{tabular}

Tabel 2 menunjukkan terdapat hubungan positif langsung antara kemampuan motorik kasar dengan kualitas hidup dan secara statistik signifikan $(\mathrm{b}=2,79 ; \quad$ CI $95 \%=1,54$ hinga 4,03 ; $\mathrm{P}=<0,001)$. Anak cerebral palsy dengan kemampuan motorik yang baik akan meningkatkan logodd memiliki kualitas hidup baik sebesar 2,79 unit daripada anak dengan kemampuan motorik kasar yang buruk.

Hasil penelitian ini sejalan dengan penelitian terdahulu bahwa ada hubungan antara fungsi motorik kasar dengan kualitas hidup. Anak Cerebral Palsy dengan level fungsi motorik kasar yang lebih rendah memiliki tingkat kualitas hidup yang lebih buruk. Fungsi motorik kasar berhubungan dengan hampir semua domain kualitas hidup seperti domain pastisipasi, kesehatan fisik, fungsi fisik dan kesejahteraan emosional. Kemampuan motorik kasar yang lebih baik berhubungan dengan intensitas partisipasi anak yang lebih tinggi, hal ini berpengaruh terhadap tingkat kualitas hidup anak (Colver et al., 2014; Surender et al., 2016; Badia et al., 2016; Mohammed et al., 2016). Faktor lain yang mempengaruhi partisipasi anak yaitu nyeri dan keterbatasan fisik dalam melakukan aktivitas keseharian, hal ini berpengaruh pada penurunan kualitas hidup terutama pada aspek partisipasi dan kesehatan fisik. Fungsi fisik seperti nyeri, fungsi sensorik, fungsi mental, neuromuscular, musculoskeletal dan fungsi yang berhubungan dengan kemampuan motorik secara signitifkan mempengaruhi kualitas hidup anak (Park et al., 2019).

Hasil penelitian lain menunjukkan bahwa terdapat korelasi antara aktivitas dan partisipasi anak yang lebih tinggi dengan kualitas hidup anak. Kemampuan anak melakukan aktivitas keseharian secara mandiri dan berpartisipasi dalam kegiatan sosial membuat anak merasa mandiri. Hal ini berpengaruh pada kualitas hidup anak yang berhubungan dengan aspek partisipasi dan psikologis anak (Mei et al., 2015; Park et al., 2019).

Tabel 2 menunjukkan bahwa dukungan keluarga berhubungan positif langsung dengan kualitas hidup anak dan secara statistik signifikan $(b=1,25 ; C I \quad 95 \%=0,26$ hingga 2,24; $\mathrm{p}=0,013$ ). Anak cerebral palsy yang mendapatkan dukungan keluarga yang kuat akan meningkatkan loggodd memiliki kualitas hidup baik sebesar 1,25 unit daripada anak dengan dukungan keluarga yang lemah.

Hasil penelitian menunjukkan bahwa dukungan keluarga memiliki hubungan dengan kualitas hidup anak Cerebral Palsy. Faktor keluarga, salah satunya yaitu dukungan keluarga berhubungan dengan kualitas hidup anak (Mohammed et al., 2016). Bentuk dukungan keluarga yang diterima berupa dukungan informasi, emosional, instrumental dan penilaian. Dukungan informasi yang kuat termasuk pengetahuan dasar mengenai penyebab, gangguan yang menyertai kondisi Cerebral Palsy dan manajemen perawatan membantu orangtua lebih mengetahui kebutuhan anak sesuai dengan kondisi gangguan yang dialami. Anak Cerebral Palsy dengan kebutuhan instrumental (akses terapi dan kebutuhan alat bantu) yang memadai memungkinkan anak mendapatkan perawatan yang baik, meningkatkan fungsi aktivitas keseharian dan partisipasi anak. Peningkatan 
A N Ramadhani \& D L Romadhoni / Jurnal Kesehatan 14 (2) 2021, 223-229

fungsi aktivitas keseharian dan partisipasi ini kemudian berpengaruh terhadap kualitas hidup anak (Ramadhani et al., 2018).

Anak yang mendapatkan dukungan emosional yang baik akan merasa diterima, diperhatikan dan menerima kasih sayang yang cukup dalam keluarga. hal ini akan berpengaruh terhadap aspek kesejahteraan emosional anak. Dukungan keluarga yang diterima orangtua kemudian akan membentuk sikap keluarga terhadap penanganan anak Cerebral Palsy serta mendorong untuk mengupayakan penanganan anak semaksimal yang bisa mereka dapatkan (Harumi et al., 2017; Tessier et al., 2014).

Tabel 2 menunjukkan bahwa dukungan sosial berhubungan positif langsung dengan kualitas hidup anak dan secara statistic signifikan $(b=0,99$; CI 95\% $=$ $0,014$ hingga 1,$97 ; p=0,047)$. Anak cerebral palsy yang mendapatkan dukungan sosial yang kuat akan meningkatkan logodd memiliki kualitas hidup baik sebesar 0,99 unit daripada anak dengan dukungan sosial yang lemah.

Dukungan sosial yang kuat dikaitkan dengan peningkatan kualitas hidup anak. Dukungan sosial dengan memfasilitasi koordinasi perawatan dengan pihak-pihak lain selain keluarga dan perawatan berbasis keluarga berhubungan dengan peningkatan kualitas hidup anak pada aspek psikososial (Tessier et al., 2014). Perawatan berbasis keluarga berhubungan dengan peran komunitas, pemenuhan finasial dan dukungan sosial yang sesuai dengan kebutuhan perawatan anak (Almasari et al., 2013).

Penanganan yang baik ini berdampak pada perkembangan kondisi kesehatan anak yang kemudian mempengaruhi kesehatan fisik anak, kemampuan dan partisipasi anak. Peningkatan ini kemudian akan berpengaruh pada kualitas hidup anak (Harumi et al., 2017).

\section{KESIMPULAN}

Berdasarkan hasil path analysis, kemampuan motorik kasar, dukungan keluarga, dan dukungan sosial berhubungan langsung dengan kualitas hidup anak cerebral palsy.

Saran untuk penelitian selanjutnya adalah diharapkan dapat mengembangkan penelitian terkait faktor-faktor yang mempengaruhi kualitas hidup anak cerebral palsy menggunakan berbagai metode analisis berbeda seperti multilevel analisis atau menambahkan variabel lain yang belum diteliti.

\section{DAFTAR PUSTAKA}

Almasri, A., O’Nell M.E., Palisano, R.J. (2013). Predictors of Needs for Families of Children with Cerebral Palsy. Disability and Rehabilitation, 145(2), 1-10.

Badia, M., Begoña Orgaz, M., Gómez-Vela, M., Verdugo, M. A., Ullán, A. M., \& Longo, E. (2016). Do environmental barriers affect the parent-reported quality of life of children and adolescents with cerebral palsy? Research in Developmental Disabilities, 49 50(October), 312-321. https://doi.org/10.1016/j.ridd.2015.12.011

Boling, S., Tarja, V., Helena, M., Wivi, F., Ilona, A.R \& Leena, H. (2013). Measuring quality of life of Finnish children with Palsi Serebralis. J Pediatr Rehabilit Med, 6: 121-7.

Chen, K. L., Tseng, M. H., Shieh, J. Y., Lu, L., \& Huang, C. Y. (2014). Determinants of quality of life in children with cerebral palsy: A comprehensive biopsychosocial approach. Research in Developmental Disabilities, 35(2), 520-528. https://doi.org/10.1016/j.ridd.2013.12.002 
Colver, A., Fairhurst, C., \& Pharoah, P. O. D. (2014). Cerebral palsy. The Lancet, 383(9924), 1240-1249. https://doi.org/10.1016/S0140-6736(13)61835-8

Colver, A., Rapp, M., Eisemann, N., Ehlinger, V., Thyen, U., Dickinson, H. O., ... Arnaud, C. (2015). Self-reported quality of life of adolescents with cerebral palsy: A cross-sectional and longitudinal analysis. The Lancet, 385(9969), 705-716. https://doi.org/10.1016/S0140-6736(14)61229-0

Delacy, M. J., \& Reid, S. M. (2016). Profile of associated impairments at age 5 years in Australia by cerebral palsy subtype and Gross Motor Function Classification System level for birth years 1996 to 2005. Developmental Medicine \& Child Neurology, 58, 50 56. https://doi.org/10.1111/dmcn.13012

Dickinson, H. O., Parkinson, K. N., Ravens-Sieberer, U., Schirripa, G., Thyen, U., \& Arnaud, C. (2007). Self-reported quality of life of 8-12-year-old children with cerebral palsy: a multi-centre cross-sectional European Study. Lancet, 369(9580), 2171-2178.

Harumi, L., Pamungkasari, E.P., Murti, B. (2017). Effectiveness of Practical Integrative Modul in Empowering Family of Children With Cerebral Palsy. Journal of Health Promotion and Behaviour, 2(2): 174-183. https://doi.org/10.26911/thejhpb.2017.02.02.07

Jeffries, L., Fiss, A., McCoy, S. W., \& Bartlett, D. J. (2016). Description of Primary and Secondary Impairments in Young Children With Cerebral Palsy. Pediatric Physical Therapy, 28(1), 7-14. https://doi.org/10.1097/PEP.0000000000000221

Mei, C., Reilly, S., Reddinhough, D., Mensah, F., Green, J., Pennington, L., Morgan, A.T. (2015). Activities and participation of children with cerebral palsy: parent perspectives. Disability and Rehabilitation, 37:23, 2164-2173. https://doi.org/10.3109/09638288.2014.999164

Mohammed, F. S., Ali, S., \& Mustafa, M. A. (2016). Quality of life of cerebral palsy patients and their caregivers: A cross sectional study in a rehabilitation center Khartoum-Sudan (2014 - 2015). Journal of Neurosciences in Rural Practice, 7(3), 355. https://doi.org/10.4103/0976-3147.182778

Oskui, M., Coutinho, F., Dykeman, J., Jette, N., \& Pringsheim, T. (2013). An update on the prevalence of cerebral palsy: A systematic review and meta-analysis. Developmental Medicine and Child Neurology, 55: 509-519.

Park, S.K., Yang, D.J., Heo, J.W., Kim, J.H., Park, S.H., Uhm, Y.H. (2016). Study on the quality of life of children with cerebral palsy. The Journal of Physical Therapy Science, 28 (11): 3145-3148.

Rosenbaum, P., Paneth, N., Leviton, A., Goldstein, M., Bax, M., Damiano, D., Jacobsson, B. (2007). A report: The definition and classification of cerebral palsy April 2006. Developmental Medicine and Child Neurology, 49(SUPPL.109), 814.https://doi.org/10.1111/j.1469-8749.2007.tb12610.x

Ramadhani, A. N., Adriani, R. B., Salimo, H. (2018). Path Analysis on the Biopsychosocial Determinants of Quality of Life among Children with Cerebral Palsy. Journal of Maternal and Child Health, 3(4): 301-307. 
A N Ramadhani \& D L Romadhoni / Jurnal Kesehatan 14 (2) 2021, 223-229

Surender, S., Gowda, V., Sanjay, K., Basavaraja, G., Benakappa, N., \& Benakappa, A. (2016). Caregiver-reported health-related quality of life of children with cerebral palsy and their families and its association with gross motor function: A South Indian study. Journal of Neurosciences in Rural Practice, 7(2), 223. https://doi.org/10.4103/0976-3147.178657

Tessier D.W., Hefner, J.L., Newmeyer, A. (2014). Factors Related to Psychosocial Quality of Life for Children With Cerebral Palsy. International Journal of Pediatris. http://dx.doi.org/10.1155/2014/204386 